\title{
Parametric Study on the Effect of Aspect Ratio of Selected Cooling Hole Geometries on the Mechanical Response of an Automobile Aluminium Alloy Wheel
}

\author{
S. O. Igbudu1, D. A. Fadare ${ }^{2}$ \\ ${ }^{1}$ Mechanical Engineering Department, Ambrose Alli University, Ekpoma, Nigeria \\ ${ }^{2}$ Mechanical Engineering Department, University of Ibadan, Ibadan, Nigeria \\ Email: samigbudu@yahoo.com, fadareda@yahoo.com
}

How to cite this paper: Igbudu, S.O. and Fadare, D.A. (2021) Parametric Study on the Effect of Aspect Ratio of Selected Cooling Hole Geometries on the Mechanical Response of an Automobile Aluminium Alloy Wheel. Open Journal of Applied Sciences, 11, 41-57.

https://doi.org/10.4236/ojapps.2021.111004

Received: November 13, 2020

Accepted: January 15, 2021

Published: January 18, 2021

Copyright $\odot 2021$ by author(s) and Scientific Research Publishing Inc. This work is licensed under the Creative Commons Attribution International License (CC BY 4.0).

http://creativecommons.org/licenses/by/4.0/

(c) (i) Open Access

\begin{abstract}
Aluminium alloy wheels are increasingly popular for their light weight and good thermal conductivity. Cooling Holes $(\mathrm{CH})$ are introduced to reduce their weight without compromising structural integrity. Literature is sparse on the effect of aspect ratio (AR) of $\mathrm{CHs}$ on wheels. This, work, therefore, attempts to undertake a parametric study of the effect of aspect ratio (AR) on the mechanical response of an aluminium alloy wheel with triangular, quadrilateral and oval-shaped CHs. Three-dimensional wheel models (6JX14H2ET42) with triangular, quadrilateral and oval shaped $\mathrm{CH}$ (each with $\mathrm{CH}$ area of $2229 \mathrm{~mm}^{2}$ ) were generated, discretized, and analyzed by FEM using Creo Elements/Pro 5.0 to determine the mechanical response at the inboard bead seat at different ARs of $1,0.5,0.33$ and 0.25 , each for quadrilateral- $\mathrm{CH}$ and oval- $\mathrm{CH}$, at a static Radial Load of $4750 \mathrm{~N}$ and Inflation Pressures of 0.3 and $0.15 \mathrm{MPa}$, respectively. The study shows that the magnitude of stress and displacement is affected by shape and AR of $\mathrm{CH}$. From the results, it could be established that oval-shaped- $\mathrm{CH}$ wheel at $\mathrm{AR}$ of 0.5 offers greater prospect in wheel design as it was least stressed and deformed and, that the $\mathrm{CH}$ combination with highest integrity was the oval- $\mathrm{CH}$ and quadrilateral- $\mathrm{CH}$ at $\mathrm{AR}$ of 0.5 .
\end{abstract}

\section{Keywords}

Aluminum Alloy Wheel, Cooling Hole Geometry, Aspect Ratio, Mechanical Response

\section{Introduction}

Automobile wheels are vital structural members of the vehicular suspension sys- 
tem that sustain both static and dynamic loads encountered in operation [1]. The designs of wheels are directed by a series of international standards and codes such as the British Standards Institution and the Tire and Rim Association. Generally, wheels classified are according to their configuration (offset) as central, inset or outset [2].

Aluminium alloy wheels are increasingly popular for their light weight and good thermal conductivity. However, there are efforts to introduce $\mathrm{CHs}$ to reduce their weight without compromising structural integrity. Cooling holes are very vital in automobile wheels as they help in weight reduction, aesthetics and aid in dissipation of heat. Varieties of cooling holes are in use [3].

A lot of experimental, numerical and parametric studies have been undertaken to study the mechanical response in terms of stress and displacement of wheels using different FEM analytical tools.

Analogy from thick ring theory in the development of loadings on links and eye-bar has been analyzed [1] [4]. Outcomes demonstrate that the loading shape is of a cosine function about a central angle of about $30^{\circ}$ from either side of the point of contact with the ground contact angle $40^{\circ}$ and $90^{\circ}$ that are also assumed. Work on the exact loading function is still ongoing [4].

Without compromising fatigue resistance and other mechanical properties, using Finite Element analysis, radial fatigue and damage analysis for weight optimization of aluminum alloy wheel were examined [5] [6]. Results showed that a weight reduction of about $50 \%$ was achieved when compared to steel wheel and that damage on the wheel was about $0.2 \%$ in the flange region.

A parametric study of radial and spiral models of Al 356.2 and ZK60A alloy, respectively was undertaken. The design and analysis were executed using CREO and ANSYS, respectively. Results showed that models with spiral flexure offer greater resistance to stress than radial flexure [7].

The effect of various materials and detailed fatigue life of the automotive wheel rim by using finite element analysis and radial load testing was reviewed. Modeling of the wheel was with CATIA and imported into ANSYS for analysis. In the modern technological advancement, considerable attempts are being made to develop $\mathrm{Al}$ and $\mathrm{Mg}$ alloy wheels bearing in mind factors such as strength to weight ratio, low cost and better fuel consumption [8] [9] [10]. Most aluminium alloy wheel manufacturing companies carry different test on their products, but method of testing is always limited [11]. Results showed that, for a simulated rotary bending fatigue test at different stress levels on aluminium alloy (Al) A356.2, cracks were initiated at the joint between the arm and the hub, while the wheel mounting face lug region of the wheel experienced most stress [12] [13].

The through process modelling methodology to predict the fatigue life of A356 automobile wheel subjected to bending fatigue was investigated [14]. The through process methodology includes: 1) casting, 2) heat treatment, 3) machining, 4) in-service loading, and 5) performance prediction. Both the cyclic elastic strains measured and crack initiation for predicted cycle were in agree- 
ment with fatigue test on the wheels. Previous research studies have established the practicality and validity of the through process. [15] [16] [17].

Assessment of the wheel performance as a function of the rim and disc thickness was carried out using fatigue analysis and employing NASTRAN [18] [19]. The analytical result of stress and fatigue life was in good agreement with that obtained for rotary cornering fatigue test.

Experimental and numerical simulation of dynamic impact loading of cast aluminum alloy wheel owing to collision with the curb of the road or large obstacle was studied [20]. The result obtained showed that the maximum stress occurred in the lug region of the bolt hole as a result of geometrical complexities [13] [20]. In the study of different size wheels using ABAQUS and empirical analysis, results with good agreement were obtained [21]. Results from further works showed that stress concentrations occurred in the spoke area of the rim and cracks formation began in these areas [22].

The studies above show that for dynamic analysis of wheels, the most stressed location of the wheel is the bolt holes and the arms, while for static analysis, the most severe location is the inboard bead seat. However, literature is sparse on the effect of aspect ratio (AR) of CHs on wheels, hence, an attempt is made on this sturdy.

\section{Constitutive Stress-Strain Relations}

In the case of linearly elastic isotropic three-dimensional solid [23], the stress-strain relations are:

$$
\begin{gathered}
\sigma=\left\{\begin{array}{l}
\sigma_{x x} \\
\sigma_{y y} \\
\sigma_{z z} \\
\sigma_{x y} \\
\sigma_{y z} \\
\sigma_{z x}
\end{array}\right\}=D \varepsilon \\
D=\left\{\begin{array}{l}
\varepsilon_{x x} \\
\varepsilon_{y y} \\
\varepsilon_{z z} \\
\varepsilon_{x y} \\
\varepsilon_{y z} \\
\varepsilon_{z x}
\end{array}\right\}
\end{gathered}
$$

where the matrix $D$ is given by:

$$
[D]=\frac{E}{(1+v)(1-2 v)}\left[\begin{array}{cccccc}
1-v & v & v & 0 & 0 & 0 \\
v & 1-v & 0 & 0 & 0 & 0 \\
v & v & 1-v & 0 & 0 & 0 \\
0 & 0 & 0 & (1-2 v) / 2 & 0 & 0 \\
0 & 0 & 0 & 0 & (1-2 v) / 2 & 0 \\
0 & 0 & 0 & 0 & 0 & (1-2 v) / 2
\end{array}\right]
$$


For solids of revolution (axisymmetric solids), $[D]$ is given as:

$$
[D]=\frac{E}{(1+v)(1-2 v)}\left[\begin{array}{cccc}
1-v & v & v & 0 \\
v & 1-v & v & 0 \\
v & v & 0 & 0 \\
0 & 0 & 0 & (1-2 v) / 2
\end{array}\right]
$$

For the tetrahedron element is shown in Figure 1 with global $x y z$ coordinate system and having twelve nodal degrees of freedom and three displacement components $u, v$ and $w$, the displacement variation is taken to be linear as,

$$
\begin{gathered}
u(x, y, z)=\alpha_{1}+\alpha_{2} x+\alpha_{3} y+\alpha_{4} z \\
v(x, y, z)=\alpha_{5}+\alpha_{6} x+\alpha_{7} y+\alpha_{8} z \\
w(x, y, z)=\alpha_{9}+\alpha_{10} x+\alpha_{11} y+\alpha_{12} z
\end{gathered}
$$

where, $\alpha_{1}, \alpha_{2}, \cdots, \alpha_{12}$ are constants. By using the nodal coordinates,

$$
\begin{aligned}
& u=Q_{3 i-2} ; v=Q_{3 i-1} ; w=Q_{3 i} \text { at }\left(x_{i}, y_{i}, z_{i}\right) \\
& u=Q_{3 j-2} ; v=Q_{3 j-1} ; w=Q_{3 j} \text { at }\left(x_{i}, y_{i}, z_{i}\right)
\end{aligned}
$$

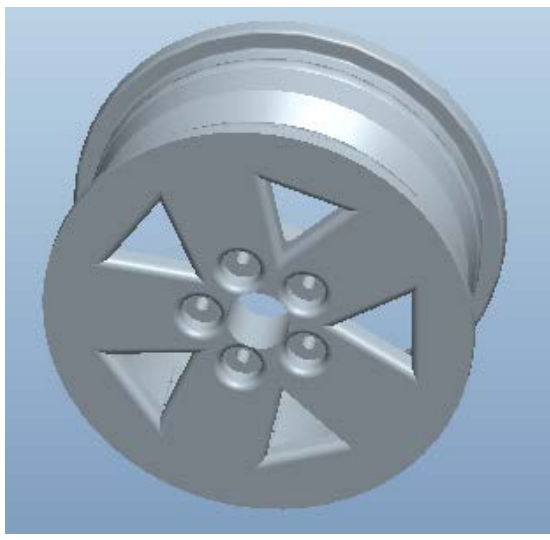

(a)

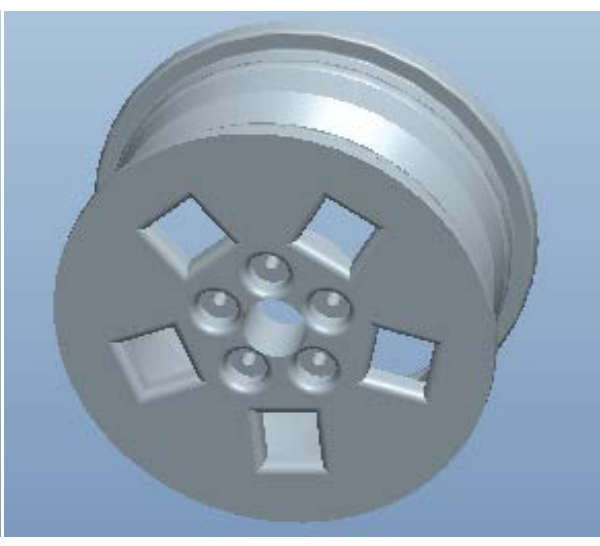

(b)

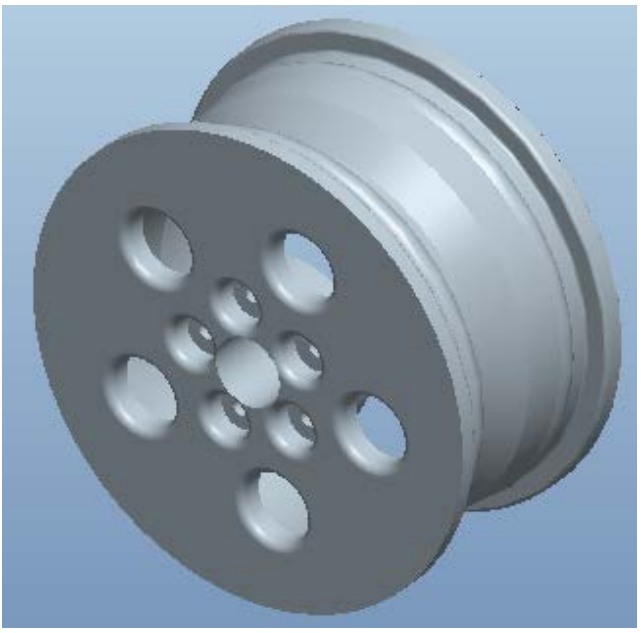

(c)

Figure 1. Cooling holes AR of 1: (a) Triangular (equilateral); (b) Quadrilateral; (c) Oval. 


$$
\begin{gathered}
u=Q_{3 k-2} ; v=Q_{3 k-1} ; w=Q_{3 k} \text { at }\left(x_{i}, y_{i}, z_{i}\right) \\
u=Q_{3 l-2} ; v=Q_{3 l-1} ; w=Q_{3 l} \text { at }\left(x_{i}, y_{i}, z_{i}\right)
\end{gathered}
$$

From it is obtained

$$
\begin{aligned}
u(x, y, z)= & N_{i}(x, y, z) Q_{3 i-1}+N_{j}(x, y, z) Q_{3 j-1} \\
& +N_{k}(x, y, z) Q_{3 k-1}+N_{l}(x, y, z) Q_{3 l-1}
\end{aligned}
$$

where, $N_{p}, N_{p} N_{k}$ and $N_{l}$ are the shape functions.

The field variable is expressed, as follows, in matrix form

$$
u=\left\{\begin{array}{l}
u(x, y, z) \\
v(x, y, z) \\
w(x, y, z)
\end{array}\right\}=[N] Q^{(e)}
$$

where,

$$
N=\left[\begin{array}{cccccccccccc}
N_{i} & 0 & 0 & N_{j} & 0 & 0 & N_{k} & 0 & 0 & N_{l} & 0 & 0 \\
0 & N_{i} & 0 & 0 & N_{j} & 0 & 0 & N_{k} & 0 & 0 & N_{l} & 0 \\
0 & 0 & N_{i} & 0 & 0 & N_{j} & 0 & 0 & N_{k} & 0 & 0 & N_{l}
\end{array}\right]
$$

noting that all the six strain components are relevant in three-dimensional analysis, the strain-displacement relation can be expressed using equation as,

$$
\begin{aligned}
& \varepsilon=\left\{\begin{array}{c}
\varepsilon_{x x} \\
\varepsilon_{y y} \\
\varepsilon_{z z} \\
\varepsilon_{x y} \\
\varepsilon_{y z} \\
\varepsilon_{z x}
\end{array}\right\}=\left\{\begin{array}{c}
\frac{\partial u}{\partial x} \\
\frac{\partial v}{\partial y} \\
\frac{\partial w}{\partial z} \\
\frac{\partial u}{\partial y}+\frac{\partial v}{\partial x} \\
\frac{\partial v}{\partial z}+\frac{\partial w}{\partial y} \\
\frac{\partial w}{\partial x}+\frac{\partial u}{\partial z}
\end{array}\right\}=[B] Q^{(e)} \\
& {[B]=\frac{1}{6 V}\left[\begin{array}{cccccccccccc}
b_{i} & 0 & 0 & b_{j} & 0 & 0 & b_{k} & 0 & 0 & b_{l} & 0 & 0 \\
0 & c_{i} & 0 & 0 & c_{j} & 0 & 0 & c_{k} & 0 & 0 & c_{l} & 0 \\
0 & 0 & d_{i} & 0 & 0 & d_{j} & 0 & 0 & d_{k} & 0 & 0 & d_{l} \\
c_{i} & b_{i} & 0 & c_{j} & b_{j} & 0 & c_{k} & b_{k} & 0 & c_{l} & b_{i} & 0 \\
0 & d_{i} & c_{i} & 0 & d_{j} & c_{j} & 0 & d_{k} & c_{k} & 0 & d_{l} & c_{l} \\
d_{i} & 0 & b_{i} & d_{j} & 0 & b_{j} & d_{k} & 0 & b_{k} & d_{l} & 0 & b_{i}
\end{array}\right]}
\end{aligned}
$$

The stiffness matrix of the element in the global system is written as,

$$
[K]^{e}=\iiint[B]^{\mathrm{T}}[D][B] \mathrm{d} v
$$

where, $[D]$ is as expressed by Equation (3). 


\section{Methodology}

The research work presents (FE) analysis of a selected automobile aluminum alloy wheel (6JX14H2; ET 42) for a passenger car which was loaded with a combination of inflation pressure of $0.3 \mathrm{MPa}$ and radial load of $4750 \mathrm{~N}$. The radial load was spread within a contact patch angle of $30^{\circ}$ symmetric about the point of contact of the wheel with the ground. This angle was chosen based on literature values [4] [24]. Three-dimensional wheel models of the wheel with triangular, quadrilateral and oval-shaped $\mathrm{CHs}$ (each with $\mathrm{CH}$ area of $2229 \mathrm{~mm}^{2}$ ) were generated, discretized into elements and analyzed by the FEM using Creo Elements/Pro 5.0. This area was chosen because this was the largest sized equilateral triangular- $\mathrm{CH}$ area that can be accommodated between the hub and the inner face of the wheel. The model consists of 38,493 tetrahedral elements. The wheel was constrained at the bolt holes. Static Radial load of $4750 \mathrm{~N}$ was then applied at an inflation pressure of $0.3 \mathrm{MPa}$ to determine the stress and displacement distribution at the inboard bead seat of the wheel at circumferential angles (between $0^{\circ}$ and $180^{\circ}$ ) symmetric about the wheels' point of contact with the ground. Young's Modulus, yield stress and Poison's ratio of the wheels are 22.29 $\mathrm{GPa}, 222.50 \mathrm{MPa}$ and 0.42 , respectively.

A parametric study was carried out at the inboard bead seat at different ARs for the CHs. The ARs considered for the triangular cooling hole were 1 and 0.5 respectively, while for the quadrilateral and oval $\mathrm{CHs}$, the AR each were 1, 0.5, 0.33 , and 0.2 , respectively. AR of 0.33 and 0.25 were not considered for the triangular cooling hole because beyond aspect ratio of 0.5 , the arm of the wheel snapped leaving the wheel as a hollow cylinder. The characteristic displacement and stress curves were compared with those of [4] and [24].

\section{Results and Discussion}

The Aspect ratios $\left(\mathrm{AR}_{\mathrm{s}}\right)$ of $1,0.5,0.33$ and 0.25 were considered for the cooling holes. For triangular cooling hole, the AR was terminated at 0.5 because it was observed that beyond the equilateral triangular- $\mathrm{CH}$, an $\mathrm{AR}$ of 0.5 and beyond lead to greater stress and displacement values and overlapping of $\mathrm{CHs}$ leading to snapping-off of the web or arm of the wheel, thus, resulting to an open ended cylinder. Figures 1-4 show quadrilateral shape cooling hole and oval shape cooling hole each at aspect ratio of $1,0.5,0.33$ and 0.25 , respectively.

\subsection{Comparison of Displacement Curves}

Figure 5 shows the relation between the shape of the displacement curve [4] and that obtained from this study. The results showed that maximum displacement values occur at the wheel's point of contact with the ground. The results are in good agreement as revealed by the shapes of the curves and that of Figures 6-8.

\section{Effect of Aspect Ratio on Displacement}

Figures 6-8 show the displacement curves for the $\mathrm{CHs}$. It could be seen that at 


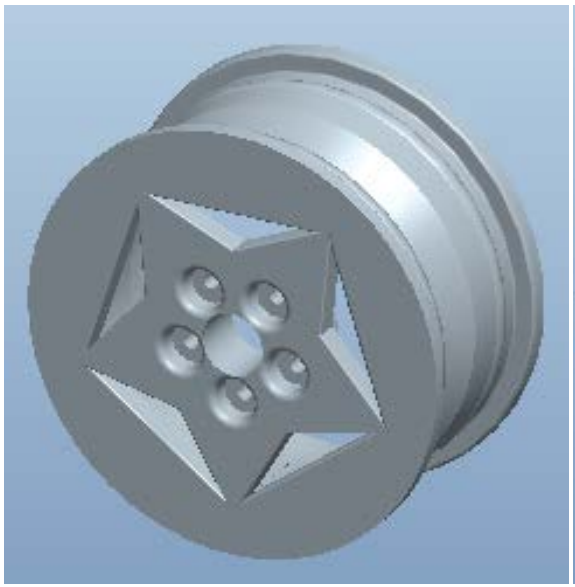

(a)

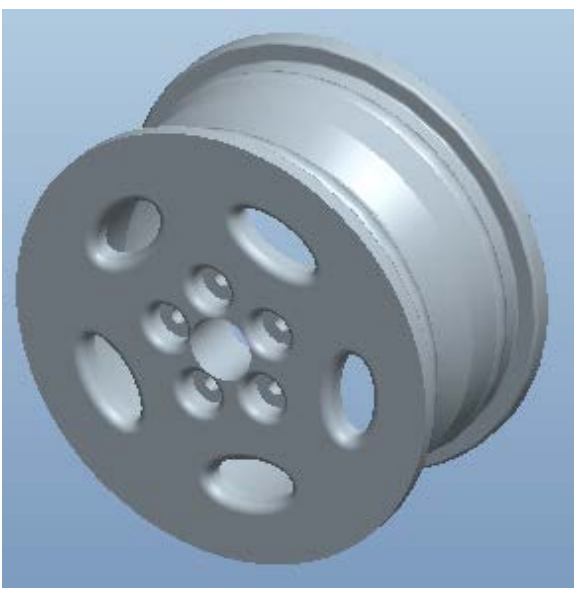

(b)

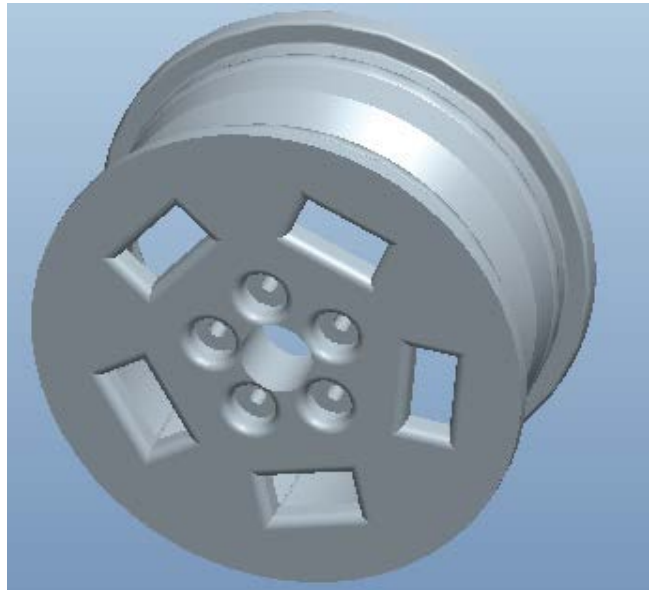

(c)

Figure 2. Cooling holes at AR of 0.5: (a) Triangular (equilateral); (b) Quadrilateral; (c) Oval.

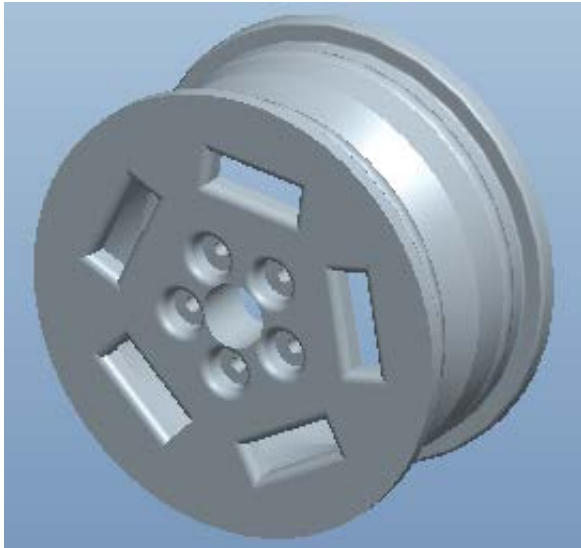

(a)

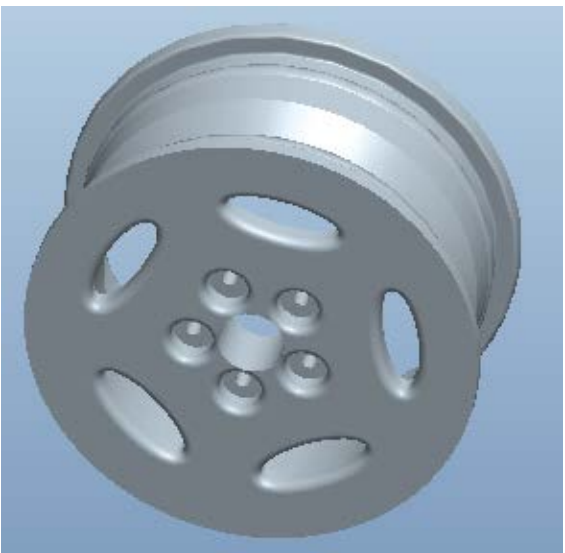

(b)

Figure 3. Cooling holes at AR of 0.33: (a) Quadrilateral; (b) Oval.

ARs of 1, 0.5, 0.33 and 0.5 , the maximum displacement values occur at the point of contact of the wheel with the ground, that is, at $0^{\circ}$ circumferential angle. The 


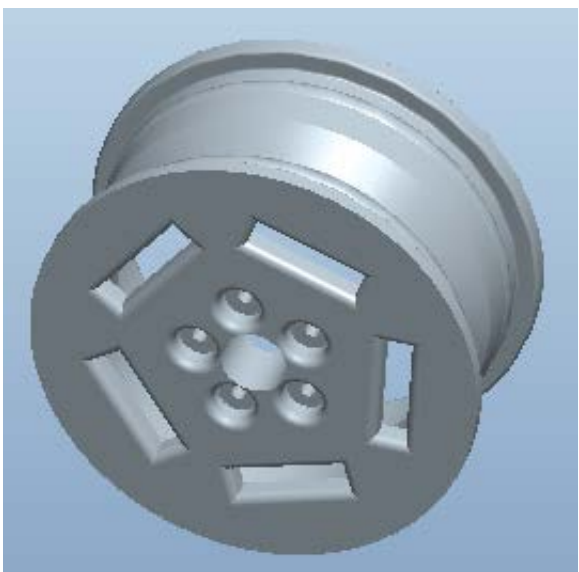

(a)

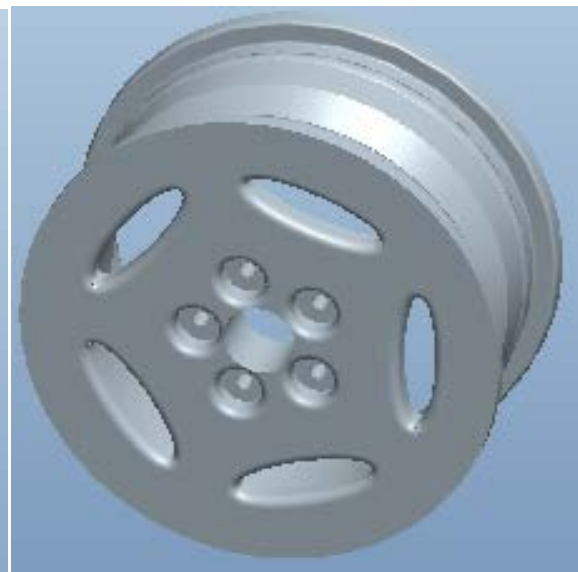

(b)

Figure 4. Cooling holes at AR of 0.25: (a) Quadrilateral; (b) Oval.

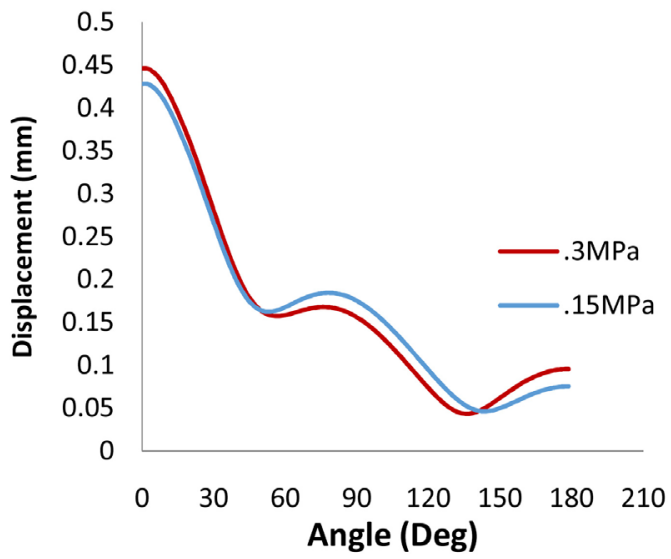

Figure 5. Displacement curves at inboard bead seat at $3114 \mathrm{~N}$ radial load [23].

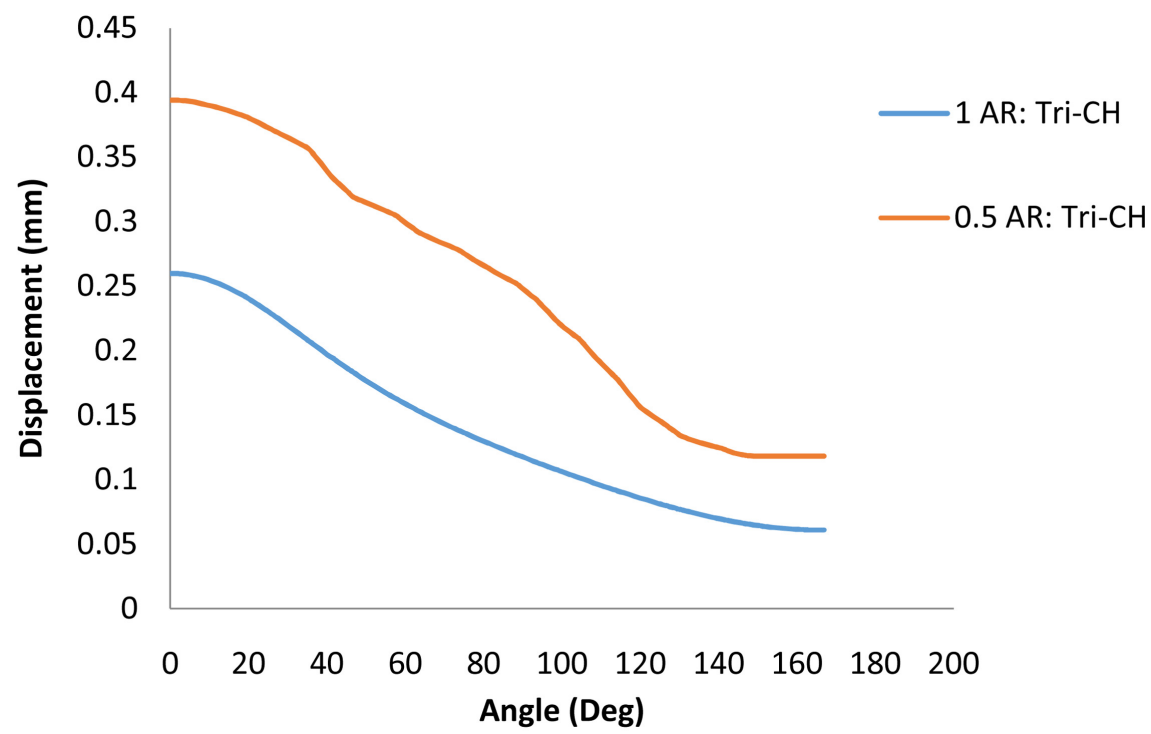

Figure 6. Displacement curves at the inboard bead seat at $4750 \mathrm{~N}$ radial load and $0.3 \mathrm{MPa}$ inflation pressure for triangular $\mathrm{CH}$. 


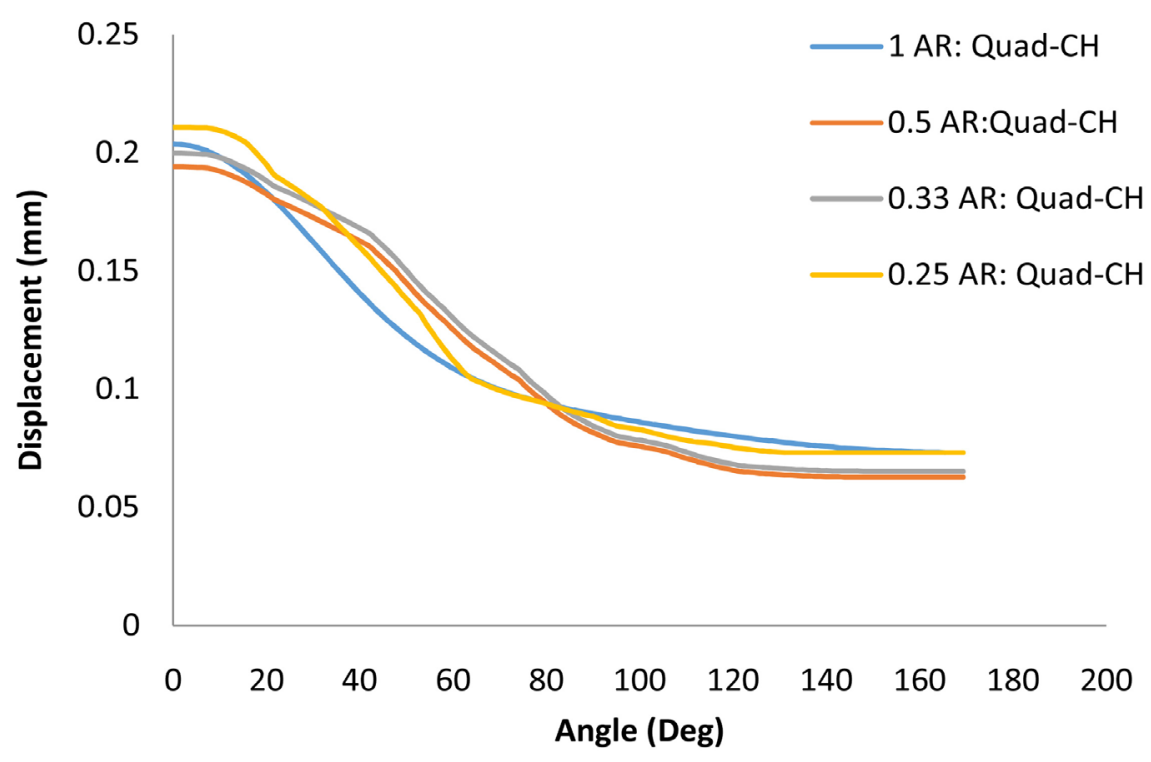

Figure 7. Displacement curves at the inboard bead seat at $4750 \mathrm{~N}$ radial load and $0.3 \mathrm{MPa}$ inflation pressure for quadrilateral $\mathrm{CH}$.

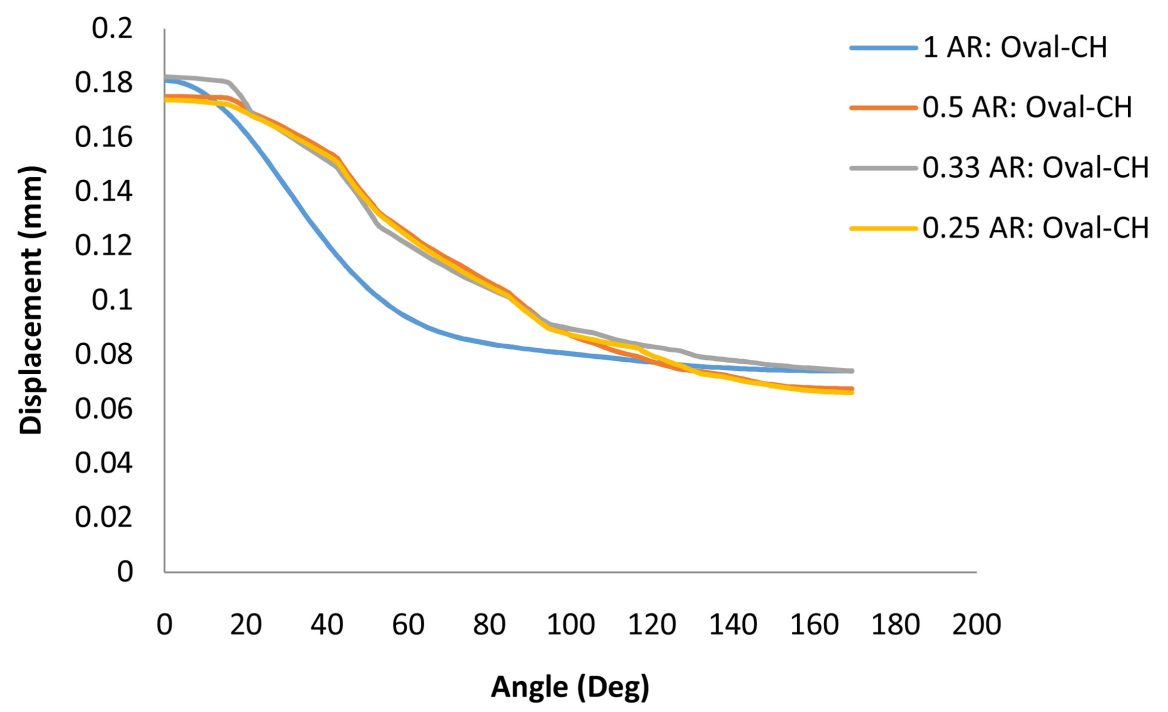

Figure 8. Displacement curves at the inboard bead seat at $4750 \mathrm{~N}$ radial load and $0.3 \mathrm{MPa}$ inflation pressure for oval $\mathrm{CH}$.

character of the curves is in good agreement with that established by literature. The, seemingly, slight variation in the shape of the curves of Figures 6-8, when compared with Figure 7, is due to the difference in the magnitude of the radial load and wheel configuration. The triangular $\mathrm{CH}$ wheel experienced maximum displaced at AR of 0.5 , with a value of about $0.414 \mathrm{~mm}$, while the least displaced wheel for the oval $\mathrm{CH}$ and quadrilateral $\mathrm{CH}$ is at $\mathrm{AR}$ of 0.5 , with a value of about $0.184 \mathrm{~mm}$ and $0.194 \mathrm{~mm}$, respectively. This implies that considering the extreme values of the displacements, the values of the oval $\mathrm{CH}$ and quadrilateral $\mathrm{CH}$ wheels will increase by about $125 \%$ and $113 \%$, respectively when compared with the wheel with triangular $\mathrm{CH}$. 


\subsection{Comparison of Von-Mises Stress}

Figure 9 shows the shape of the Von-Mises stress curve obtained by [24] as reported by [4] and sample graph from this work. Sherwood asserted that the effect of the Von-Mises stress lies between 0 degree and 40 degrees contact angle and, that beyond this angle, the effect is insignificant. The result is in good agreement as revealed by the shapes of the curves at AR of 1 for all CHs considered as shown in Figures 10-12.

\subsubsection{Effect of Aspect Ratio on Von-Mises Stress}

Figures 10-12 represent the magnitude of the stress as depicted by the shapes of the curves. It could be seen that at AR of 1 , the curves exhibited the same character as that of Figure 9. The slope is negative and the first turning point was at an angle about $40^{\circ}$ along the wheels' circumference, with maximum value at the

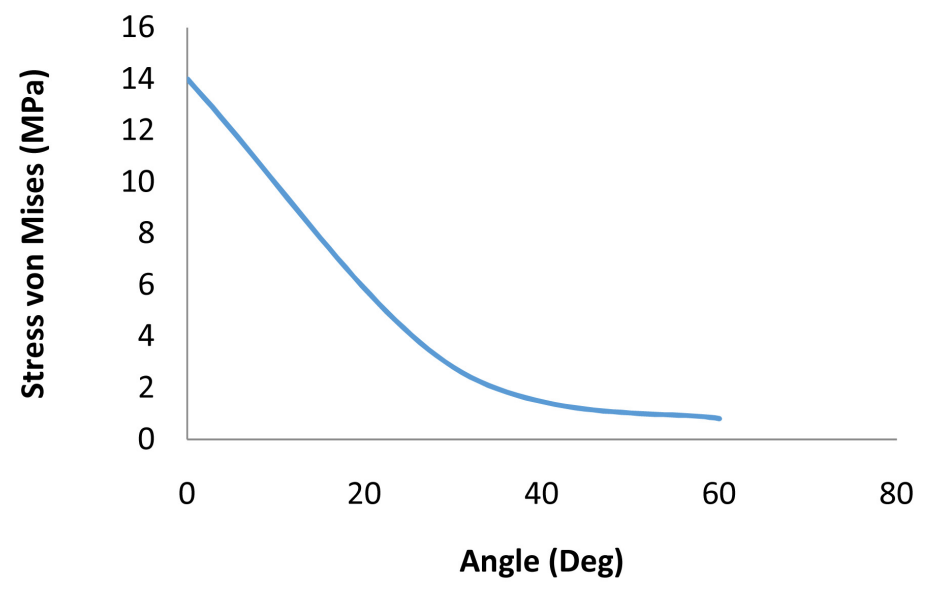

Figure 9. Von-Mises stress at inboard bead seat [4] [24].

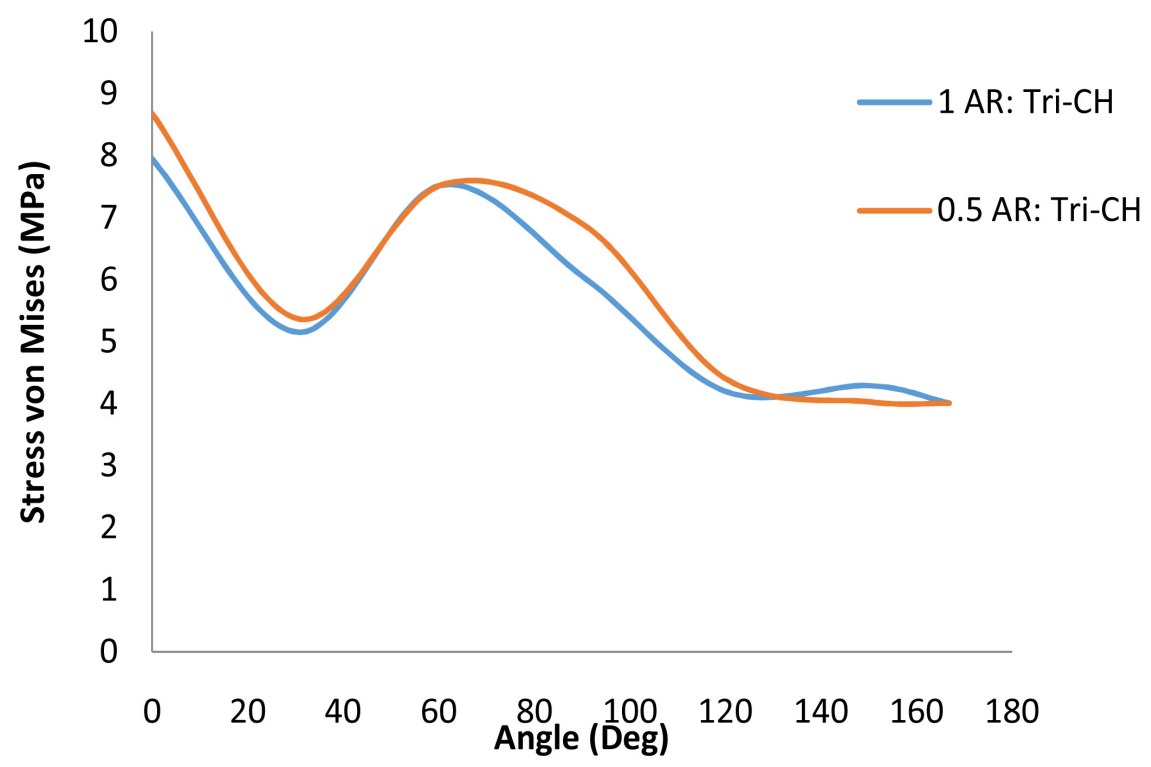

Figure 10. Von-Mises stress at the inboard bead seat at $4750 \mathrm{~N}$ radial load and $0.3 \mathrm{MPa}$ inflation pressure for triangular $\mathrm{CH}$. 


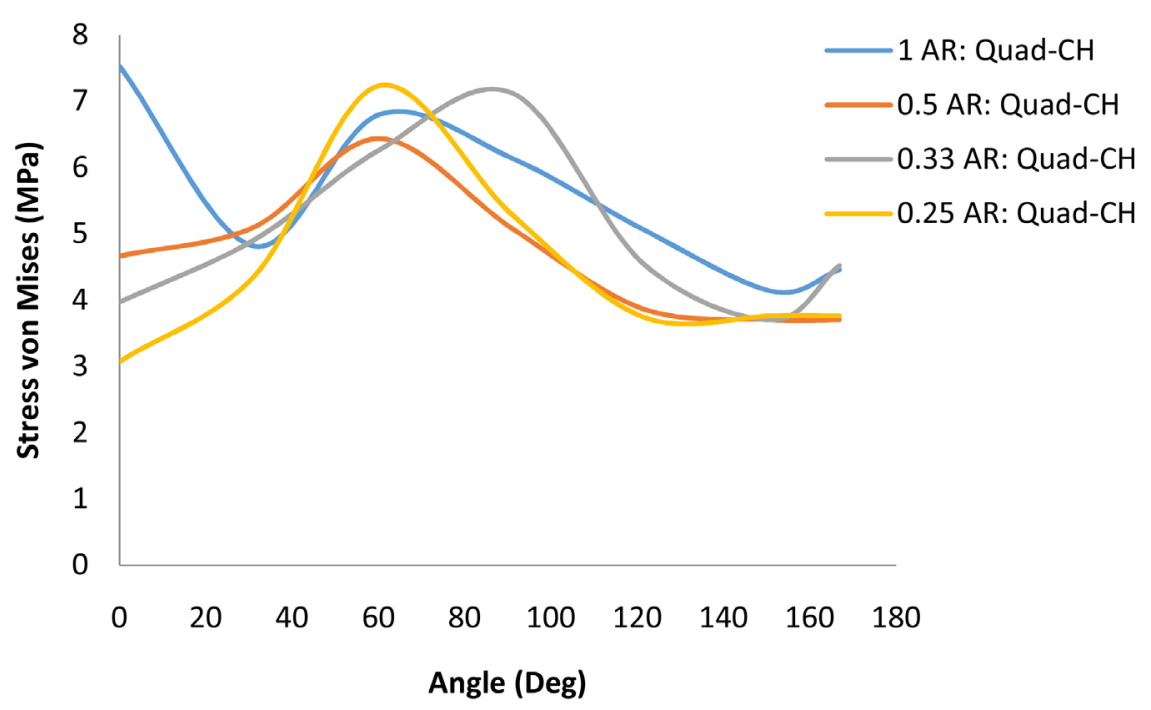

Figure 11. Von-Mises stress at the inboard bead seat at $4750 \mathrm{~N}$ radial load and $0.3 \mathrm{MPa}$ inflation pressure for quadrilateral $\mathrm{CH}$.

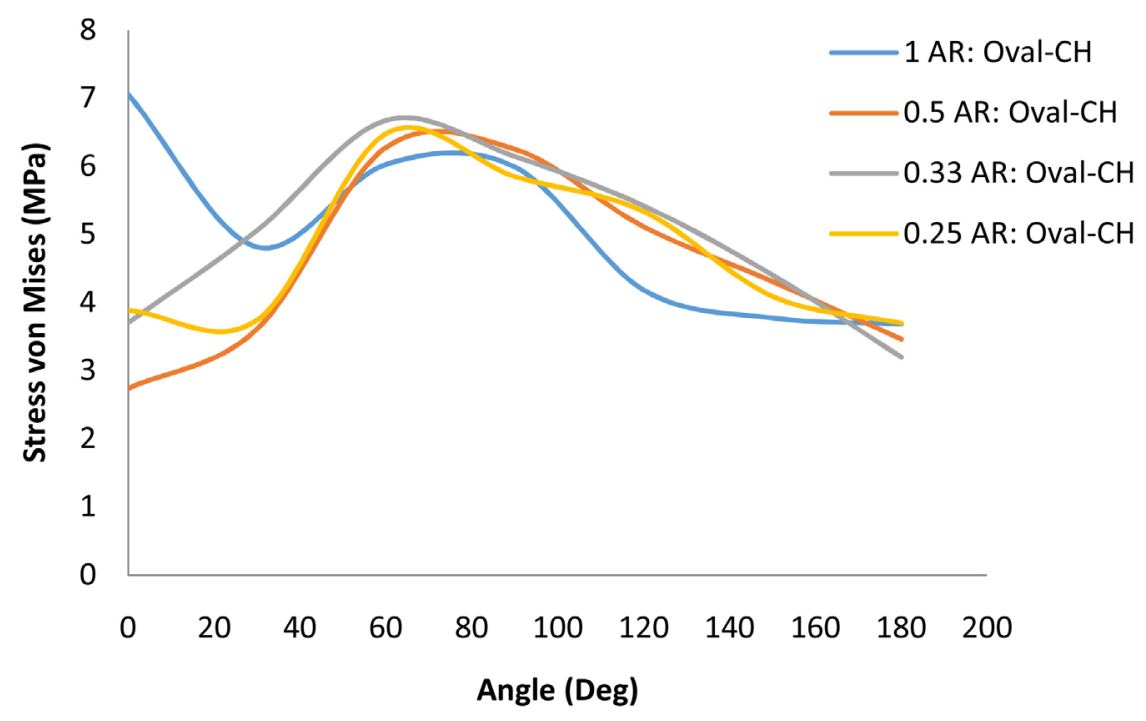

Figure 12. Von-Mises stress at the inboard bead seat at $4750 \mathrm{~N}$ radial load and 0.3 MPa inflation pressure for oval cooling hole.

point of contact with the ground, which is also in good agreement with Figure 9. The triangular $\mathrm{CH}$ wheel possesses the same attributes at $\mathrm{AR}$ of 0.5 , Figure 10 . From Figure 11 and Figure 12, At ARs of 0.5, 0.33, and 0.25, the slope is positive between $0^{\circ}$ and $40^{\circ}$ circumferential angle, with maximum Von-Mises values ranging between $40^{\circ}$ and $80^{\circ}$. The drift of the maximum displacement values may probably be due to the ARs and shape of the $\mathrm{CH}$. The maximum Von-Mises values for the triangular $\mathrm{CH}$ wheel at ARs of 1 and 0.5 are about 7.952 and 8.679 $\mathrm{MPa}$, respectively. The wheels with oval $\mathrm{CH}$ and quadrilateral $\mathrm{CH}$ is at $\mathrm{AR}$ of 0.5 , are least displaced, with values of about 6.277 and $6.433 \mathrm{MPa}$, respectively. The magnitude of stress and displacement and, shape of their curves are affected by $\mathrm{AR}$ and $\mathrm{CH}$ shape. 


\subsubsection{Effect of Cooling Hole Combination on the Mechanical Response}

Having analyzed the various $\mathrm{CH}$ geometries of triangular, quadrilateral and oval, the effect of $\mathrm{CH}$ combination was investigated at the inboard bead seat at $4750 \mathrm{~N}$ radial load and 0.3 $\mathrm{MPa}$ inflation pressure. Figures $13(\mathrm{a})-(\mathrm{c})$ show the $\mathrm{CHs}$ ' combination, viz: triangular- $\mathrm{CH}$ at $\mathrm{AR} 1$ and oval-shape- $\mathrm{CH}$ at $\mathrm{AR}$ of 0.5 ; triangular- $\mathrm{CH}$ at $\mathrm{AR} 1$ and quadrilateral- $\mathrm{CH}$ at $0.5 \mathrm{AR}$ and, quadrilateral- $\mathrm{CH}$ and oval-shape- $\mathrm{CH}$ at $0.5 \mathrm{AR}$.

Figure 14 and Figure 15 show the displacement and stress curves. It was observed that the least stress and displaced combination was quadrilateral- $\mathrm{CH}$ and oval-shape- $\mathrm{CH}$. each at $\mathrm{AR}$ of 0.5 , with a maximum displacement value at ground contact of about $0.202 \mathrm{~mm}$ and a maximum Von-Mises stress value of about 6.59 $\mathrm{MPa}$. The triangular- $\mathrm{CH}$ and oval-shape- $\mathrm{CH}$ combination had a maximum displacement value at 0 -degree location of about $0.258 \mathrm{~mm}$ and a maximum Von-Mises stress value of about 7.09 $\mathrm{MPa}$, while that of triangular- $\mathrm{CH}$ and quadrilateral- $\mathrm{CH}$ combination has a maximum displacement value of about $0.270 \mathrm{~mm}$ and a maximum Von-Mises stress value of about 7.17 MPa. The $\mathrm{CH}$ combination does not significantly affect the shape of the displacement

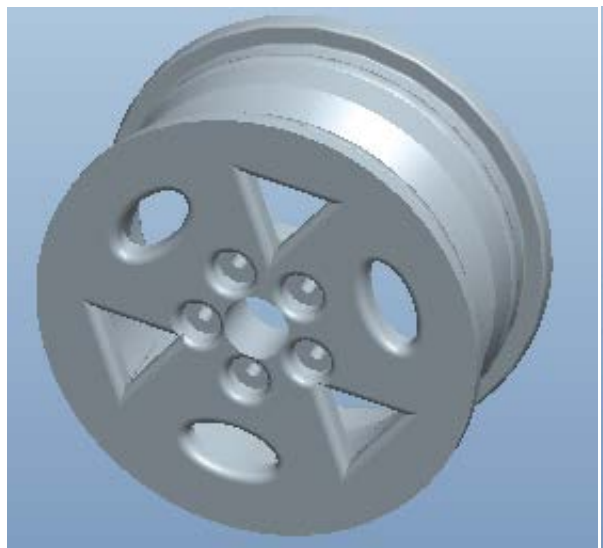

(a)

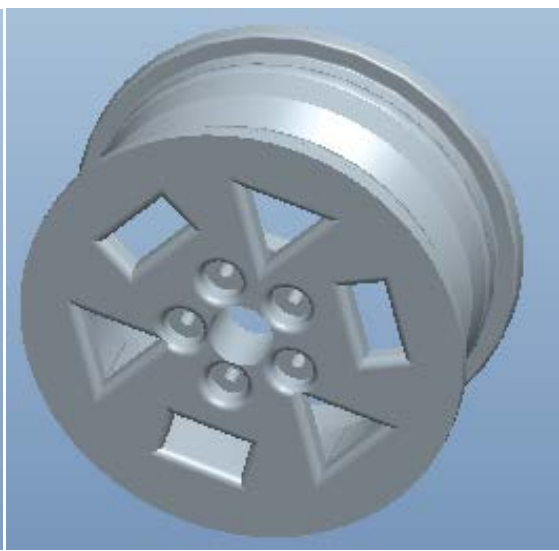

(b)

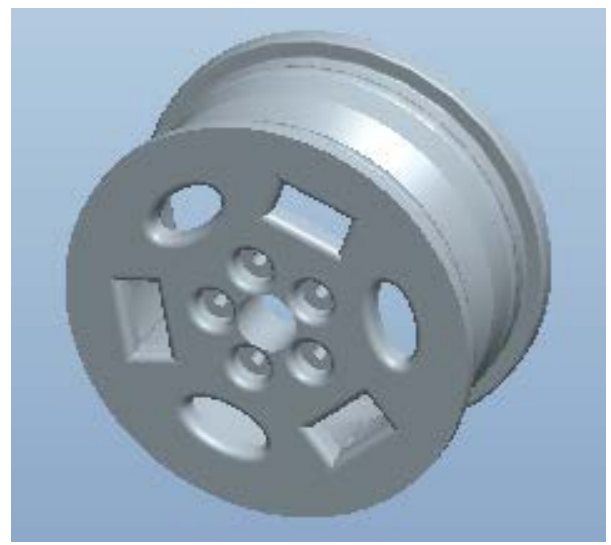

(c)

Figure 13. Cooling hole combination: (a) Triangular $\mathrm{CH}$ at $\mathrm{AR}$ of 1 and Oval $\mathrm{AR}$ of 0.5 ; (b) Triangular $\mathrm{CH}$ at $\mathrm{AR}$ of 1 and Quadrilateral $\mathrm{CH}$ AR of 0.5 ; (c) Oval AR of 0.5 and Quadrilateral CH AR of 0.5 . 


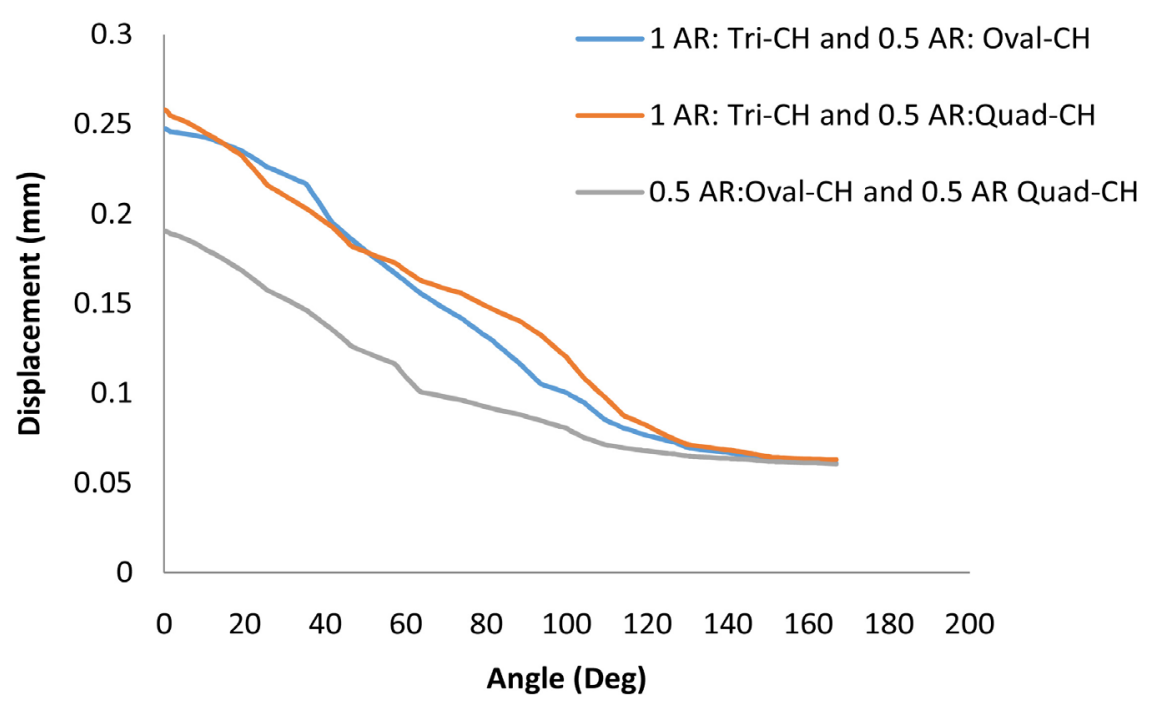

Figure 14. Effect of cooling hole combination on the displacement at the inboard bead seat at $4750 \mathrm{~N}$ radial load and $0.3 \mathrm{MPa}$ inflation pressure.

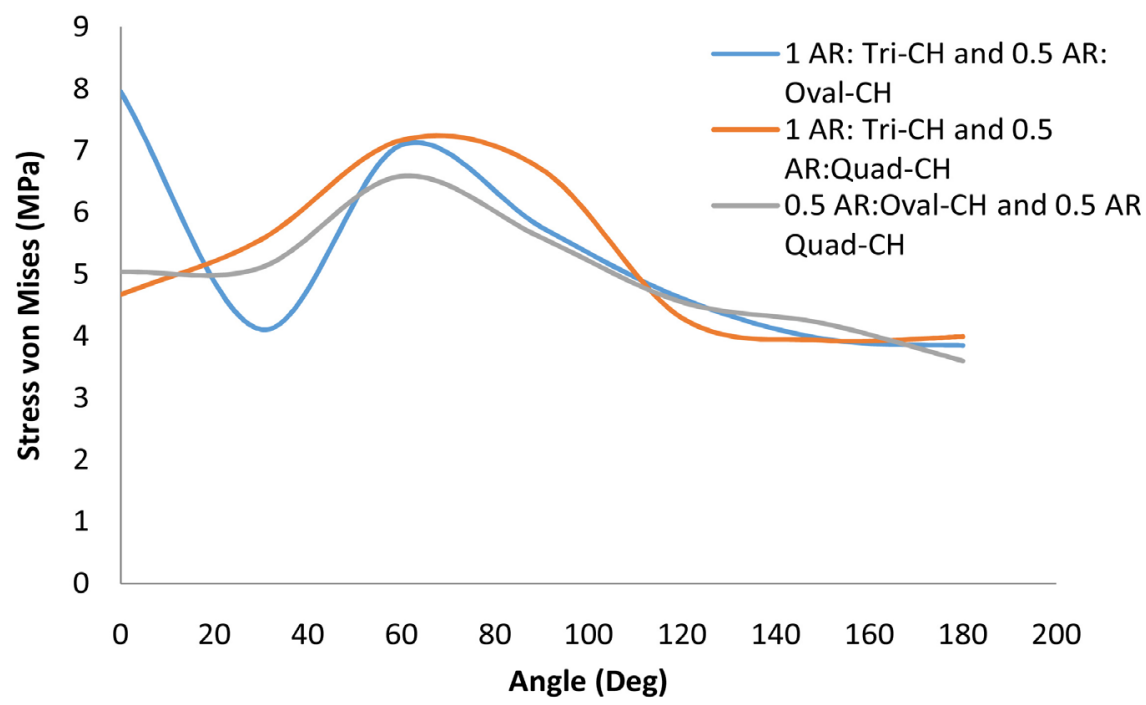

Figure 15. Effect cooling hole combination on the Von-Mises stress at the inboard bead seat at $4750 \mathrm{~N}$ radial load and $0.3 \mathrm{MPa}$ inflation pressure.

or stress curves.

Figure 16 shows the 3-D wheel model mesh; Figure 17 and Figure 18 represent displacement fringes $(\mathrm{mm})$ of different $\mathrm{CH}$ wheels at aspect ratio of 1 and 0.5 , respectively.

\section{Conclusions}

A parametric study on the effect of aspect ratio on the mechanical response of an automobile aluminium alloy wheel was undertaken. Results show that at the inboard bead seat:

1) The magnitude of stress and displacement and, shape of their curves are affected by shape and AR of $\mathrm{CH}$. 


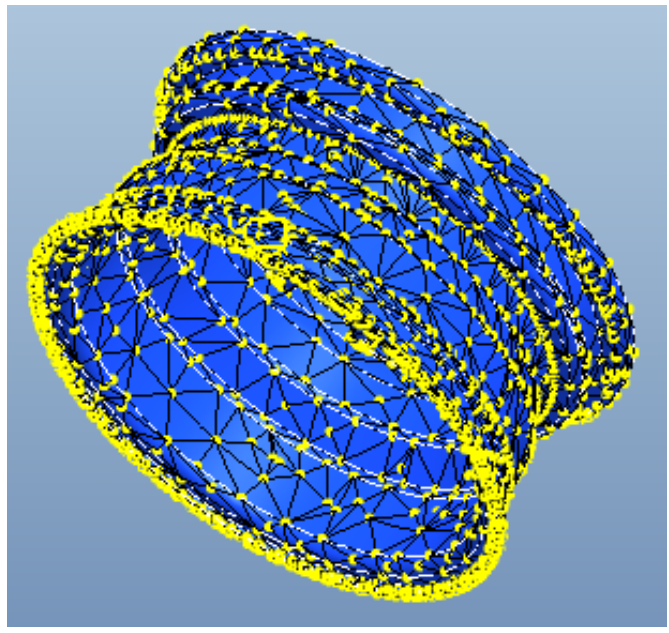

Figure 16. 3-D wheel model mesh.

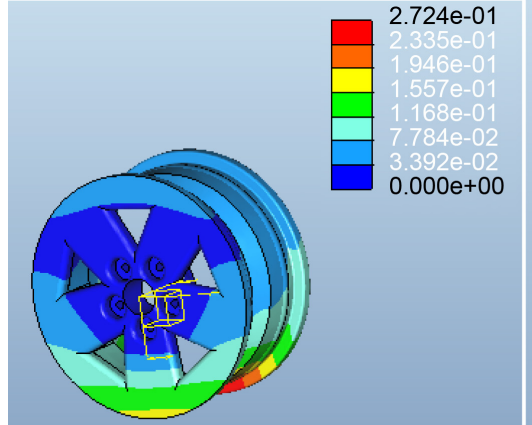

(a)

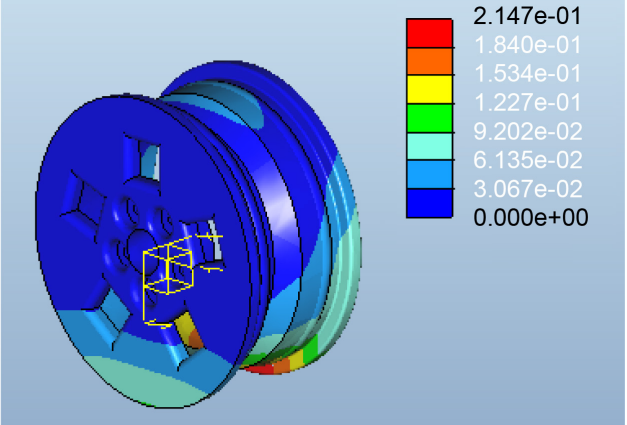

(b)

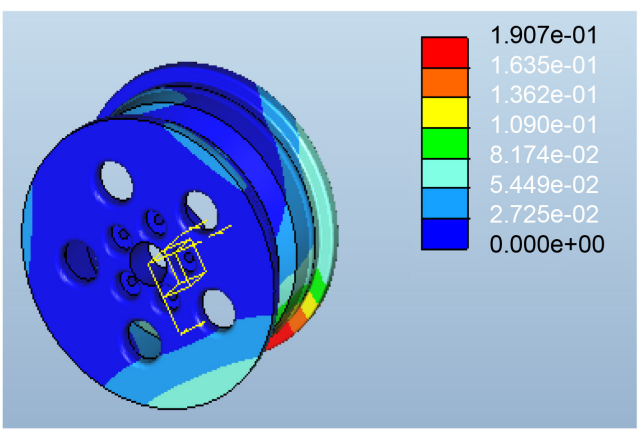

(c)

Figure 17. Displacement (mm) of wheel at aspect ratio of 1: (a) Triangular-CH; (b) Quadrilateral-CH; (c) Oval-CH.

2) Considering the extreme values, the triangular $\mathrm{CH}$ wheel is most deformed, while the oval $\mathrm{CH}$ is least deformed at $\mathrm{AR}$ of 0.5 . The maximum displacement of the wheels occurs at point of contact of the wheel with the ground, which agrees favorably with literature findings. From the results, it could be established that oval-shaped-CH wheel at AR of 0.5 offers greater prospect in wheel design as it was least stressed and deformed.

3) For the wheels at AR of 1, the maximum value of the Von-Mises stress is at point of contact with the ground. The same attribute was established for the 


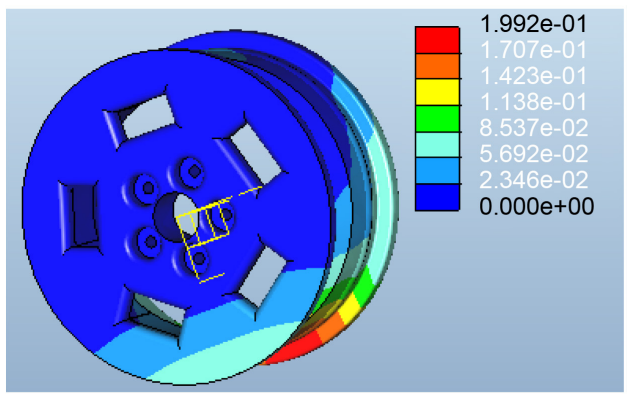

(a)

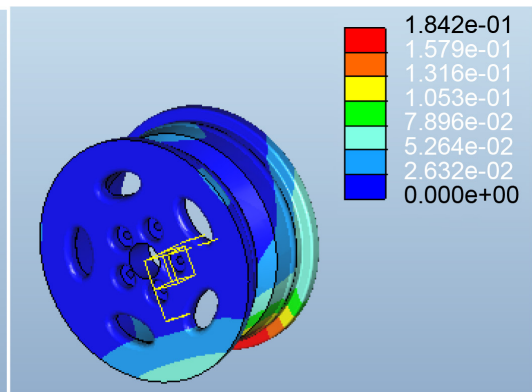

(b)

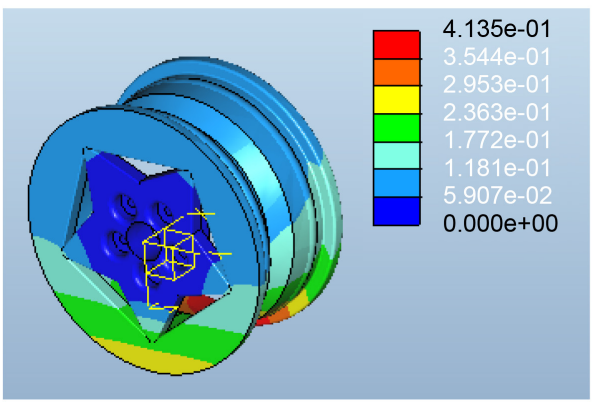

(c)

Figure 18. Displacement $(\mathrm{mm})$ of wheel at aspect ratio of 0.5 : (a) Triangular- $\mathrm{CH}$; (b) Quadrilateral-CH; (c) Oval-CH.

triangular $\mathrm{CH}$ wheel at $\mathrm{AR}$ of 0.5. Maximum Von-Mises values ranging between $40^{\circ}$ and $80^{\circ}$ contact angle both for the oval $\mathrm{CH}$ and quadrilateral $\mathrm{CH}$ wheels at AR OF $0.5,0.33$ and 0.25 . The drift in maximum displacement values may probably be due to the ARs and shape of the $\mathrm{CH}$. The $\mathrm{CH}$ combination with highest integrity was the oval and quadrilateral at AR of 0.5 .

4) This study, in itself, is not exhaustive in view of the $\mathrm{CH}$ shapes and ARs considered. Further studies in this area are encouraged.

\section{Conflicts of Interest}

The authors declare no conflicts of interest regarding the publication of this paper.

\section{References}

[1] Mohd, I.F.B.B. (2011) Simulation Test of Automotive Alloy Wheel Using Computer Aided Engineering Software.

http://umpir.ump.edu.my/id/eprint/143/1/simulation_test_of_automotive_alloy_w heel_using_computer_aid.pdf

[2] Carret, T.K., Newton, K. and Steeds, W. (2000) Chapter 41: Wheels and Tyres. Journal of Motor Vehicle, 13, 1085-1108.

https://doi.org/10.1016/B978-075064449-5/50042-0

[3] Igbudu, O.S. (2018) Analysis of the Structural Integrity of an Automobile Aluminium Alloy Wheel with Selected Cooling Hole Geometries. Ph.D. Thesis, University of Ibadan, Ibadan.

[4] Stearns, J.C. (2000) An Investigation of Stress and Displacement Distribution in 
Aluminium Alloy Automobile Rim. Ph.D. Thesis, University of Akron, Akron, 1-22, 128-170.

[5] Gergele, J. (1983) Weight of Wheels. Centre D'etudes et de Recherches Michelin, France.

[6] Das, S. (2014) Design and Weight Optimization of Aluminium Alloy Wheel. International Journal of Scientific and Research Publications, 4, No. 6.

[7] Lukhman, M.M., Naveen Kumar, M., Venkatesan, J., Kumars, S. and Srinavinapriya, D. (2017) Design and Analysis of Al 356.2 and ZK60A Wheel Rim with Radial and Spiral Flexures. International Journal of Advance Engineering and Research Development, 4, 282-290. https://doi.org/10.21090/IJAERD.60176

[8] Dasu, P. and Abhilash, L. (2016) Fatigue Analysis of Aluminum Alloy Wheel. International Journal of Research in Mechanical Engineering \& Technology, 7, 47-55.

[9] Shinde, J., Kadam, S. and Pandit, S. (2017) Review Paper on Design and Analysis of Automotive Wheel Rim Using Finite Element Analysis. International Research Journal of Engineering and Technology (IRJET), 4, 2723-2725.

[10] Razak, M.I. (2015) Design and Development of Alloy Wheel. https://www.researchgate.net/profile/Muhammad_Ikhwan_Razak

[11] Nallusamy, S., Mankanda Prabu, N., Balakannan, K. and Majumdar, G. (2015) Analysis of Static Stress in an Alloy Wheel of the Passengercar. International Journal of Engineering Research in Africa, 16, 17-25. https://doi.org/10.4028/www.scientific.net/JERA.16.17

[12] Raju, R., Satyanarayana, B., Ramji, K. and Babu, S.K. (2009) Evaluation of Fatigue Life of Aluminium Alloy Wheels under Bending Loads. Fatigue and Fracture of Engineering Materials and Structure, 32, 119-126. https://doi.org/10.1111/j.1460-2695.2008.01316.x

[13] Muhammet, C. (2010) Numerical Simulation of Dynamic Side Impact Test for an Aluminium Alloy Wheel. Scientific Research and Essays, 5, 2694-2710.

[14] Li, P., Maijer, D.M., Lindley, T.C. and Lee, P.D. (2007) A Through Process Model of the Impact of In-Service Loading, Residual Stress, and Microstructure on the Final Fatigue Life of an A356 Automobile Wheel. Material Science and Engineering: A, 460-461, 20-30. https://doi.org/10.1016/j.msea.2007.01.076

[15] Li, P., Maijer, D.M., Lindley, T.C. and Lee, P.D. (2007) Simulating the Residual Stress in an A356 Automobile Wheel and Its Impact on Fatigue Life. Metallurgical and Materials Transactions B, 38, 505-515. https://doi.org/10.1007/s11663-007-9050-5

[16] Zang, B., Maijer, D.M. and Cockcroft, S.L. (2007) Material Science. Engineering, A, 10, 2-18, in Press.

[17] Yi, J.Z., Gao, Y.X., Lee, P.D., Flower, H.M. and Lindley, T.C. (2003) Scatter in Fatigue Life Due to Effects of Porosity in Cast A356-T6 Aluminum-Silicon Alloys. $\mathrm{Me}$ tallurgical and Materials Transactions A, 34, Article No. 1879. https://doi.org/10.1007/s11661-003-0153-6

[18] Reipert, P. (1985) Optimization of an Extremely Light Cast Aluminum alloy Wheel Rim. International Journal of Vehicle Design, 6, 509-513.

[19] Mizoguchi, T., Nishimura, H., Nakata, K. and Kawakami, J. (1982) Stress Analysis and Fatigue Strength Evaluation of Sheet Fabricated 2-Piece Aluminum Alloy Wheels for Passenger Cars. Research \& Development (Kobe Steel, Ltd), 32, 25-28.

[20] Cerit, M. (2010) Numerical Simulation of Dynamic Side Impact Test for an Aluninum Alloy Wheel. Scientific Research and Essays, 5, 2694-2701. 
[21] Konishi, H., Fujiwara, A., Katsura, T., Takeuchi, K. and Nakata, M. (1996) Impact Strength of Aluminum alloy Wheel (Influence of Disk and Rim Rigidity on the JWL Impact Strength of Aluminum alloy Wheel). Nippon Kikai Gakkai Ronbunshu, CHen, 62, 2884-2890. https://doi.org/10.1299/kikaic.62.2884

[22] Stearns, J., Srivastan, T.S., Prakesh, A. and Lam, P.C. (2003) Modelling the Mechanical Response of Aluminium Alloy Automotive Rim. Material Science and Engineering. $A, 366,262-268$. https://doi.org/10.1016/j.msea.2003.08.017

[23] Rao, S.S. (1992) The Finite Element Methods in Engineering. 2nd Edition, Paragon Press PLC, Headington Hill Hall, Oxford.

[24] Sherwood, J.A., Ayres, J.M., Gross, T.S. and Watt, D. (1995) An Investigation of Tyre-Wheel Interface Loading Using ADINA. Computers \& Structures, 56, 377-387. https://doi.org/10.1016/0045-7949(95)00030-K 